\title{
Construção da paz: A interface entre abordagens nacionais e internacionais
}

Peacebuilding: The Interface between Domestic and International Approaches

Construction de la paix: l'interface entre les approches nationales et

internationales

\section{Necla Tschirgi}

Tradutor: Victor Ferreira

\section{OpenEdition}

\section{Journals}

Edição electrónica

URL: http://journals.openedition.org/rccs/5672

DOI: $10.4000 /$ rccs. 5672

ISSN: 2182-7435

\section{Editora}

Centro de Estudos Sociais da Universidade de Coimbra

Edição impressa

Data de publição: 1 Setembro 2014

Paginação: 21-44

ISSN: 0254-1106

Refêrencia eletrónica

Necla Tschirgi, "Construção da paz: A interface entre abordagens nacionais e internacionais », Revista Crítica de Ciências Sociais [Online], 104 | 2014, colocado online no dia 23 setembro 2014, criado a 04 maio 2019. URL : http://journals.openedition.org/rccs/5672 ; DOI : 10.4000/rccs.5672 


\section{NECLA TSCHIRGI}

\section{Construção da paz: A interface entre abordagens nacionais e internacionais}

$\mathrm{O}$ artigo centra-se no fosso existente entre entendimentos e abordagens nacionais e internacionais relativamente à construção da paz e nos resultados mistos que caracterizam os atuais esforços para ajudar os países devastados pela guerra. Nele, defende-se que a construção da paz no pós-Guerra Fria depende de um amplo leque de atores internacionais com interesses e mandatos diversos que não estão necessariamente em linha com as realidades e necessidades locais. Com base na abundante bibliografia sobre o papel dos atores externos em zonas de conflito, analisa-se a interface entre os atores nacionais e os internacionais através do conceito de 'hibridismo'. Em seguida, examinam-se dois mecanismos que visam nivelar o campo de atuação entre os países afetados pela guerra e os atores internacionais: a Comissão de Consolidação da Paz das Nações Unidas e o Novo Acordo para o Envolvimento em Estados Frágeis.

Palavras-chave: Comissão de Consolidação da Paz; construção da paz; Estados frágeis; resolução de conflitos.

\section{Introdução}

Desde a sua entrada no léxico da política internacional em 1992, com o muito citado relatório Uma agenda para a paz (United Nations, 1992), do, na altura, Secretário-Geral da ONU Boutros-Boutros Ghali, o termo “construção da paz" tem vindo a ser adotado nos mais diversos círculos, das agências internacionais de desenvolvimento às organizações não governamentais locais. Ao mesmo tempo, tem sido produzido um corpo impressionante de bibliografia, suscitando debates importantes sobre as características fundamentais e as principais realizações e limitações da construção da paz. ${ }^{1}$ Curiosamente, ainda não existe uma definição comummente aceite de construção da paz, o que levou à expansão constante do conceito, que inclui um leque de atividades que vai da prevenção de conflitos à reconstrução pós-conflito (Barnett et al., 2007). Após o 11 de Setembro de 2001,

\footnotetext{
${ }^{1}$ Para uma revisão das origens e da história da construção da paz, ver www.peacebuildinginitiative.org.
} 
o conceito foi ainda mais ampliado, uma vez que passou a confundir-se com construção do Estado, construção da nação, mudança de regime e intervenção humanitária. É agora usado indiscriminadamente no contexto dos combates no Afeganistão, das operações de paz no Darfur, bem como da criação de instituições a longo prazo na Serra Leoa e em Timor-Leste, o que afeta seriamente a utilidade e a credibilidade do conceito. No entanto, a construção da paz continua a ser uma área estimulante - embora controversa - para decisores políticos, profissionais e académicos.

Este artigo concentra-se num problema que continua a preocupar quer a teoria, quer a prática da construção da paz - o fosso entre entendimentos e abordagens nacionais e internacionais relativamente à construção da paz e os resultados mistos que caracterizam os atuais esforços para ajudar os países que saem de conflitos violentos. O artigo baseia-se na premissa de que a construção da paz no pós-Guerra Fria se distingue pela sua forte dependência do envolvimento da comunidade internacional. ${ }^{2}$ É cada vez mais difícil falar da construção da paz na atualidade sem fazer referência à grande variedade de atores internacionais que têm vindo a desempenhar um papel importante nos países afetados pela guerra. Estes atores normalmente têm valores, interesses e mandatos diversos (e, por vezes, conflituantes) que não estão necessariamente em linha com as realidades, necessidades ou os objetivos locais. Muito se tem escrito sobre as consequências intencionais ou não do envolvimento de atores externos em zonas de conflito (Anderson, 1999; Uvin, 1999). Com base nessa bibliografia, o foco deste artigo incide mais concretamente na interface entre atores nacionais e internacionais através da lente do conceito de hibridismo e de dois novos mecanismos com o objetivo de nivelar o campo de atuação entre os países afetados por conflitos e os seus parceiros internacionais.

$\mathrm{O}$ artigo divide-se em quatro secções. A primeira fornece uma breve visão geral sobre as aspirações e limitações da construção da paz internacional a fim de situar a problemática subjacente ao artigo no âmbito da prática e da investigação. A segunda secção revê os debates atuais sobre hibridismo como uma oportunidade para repensar as dicotomias enganadoras de externo e interno, e de cima para baixo e de baixo para cima que caracterizam o discurso de construção da paz contemporâneo. Tomando o hibridismo como uma lente útil para investigar o encontro complexo e assimétrico entre as agendas nacionais e as internacionais, a terceira secção analisa dois novos

\footnotetext{
${ }^{2}$ O termo "comunidade internacional" é um termo problemático ainda que seja amplamente usado. Neste artigo, refere-se a atores externos apenas para os distinguir dos atores nacionais. Nem os atores externos nem os nacionais são monolíticos ou homogéneos, razão pela qual o tema deste artigo é a sua interação diversificada.
} 
mecanismos que visam fortalecer as vozes dos países afetados por conflitos na conceção e prestação de assistência internacional para a construção da paz. A última secção apresenta alguns comentários finais sobre o futuro da construção da paz.

\section{O projeto internacional de construção da paz: uma visão geral}

A agenda de construção da paz no pós-Guerra Fria foi desenhada mais por necessidade do que por um projeto intencional. Ao longo da década de 1990, à medida que os conflitos duradouros da Guerra Fria chegavam ao fim e "novas guerras", emergências complexas e conflitos intraestatais eram catapultados para o centro do palco no que respeita aos assuntos internacionais, verificou-se um aumento significativo na reivindicação de que as Nações Unidas e outros atores internacionais deveriam assumir um papel concertado no auxílio a países afetados por conflitos. Inicialmente, não era evidente que forma iria esse auxílio tomar e como se iria enquadrar nas ferramentas e nos instrumentos de política e de programação existentes. No entanto, as Nações Unidas, outras organizações internacionais e regionais, agências de doadores, organizações não-governamentais e profissionais da linha da frente do desenvolvimento, dos direitos humanos e de organizações humanitárias envolveram-se numa série de atividades, projetos e programas que iam além do sistema compartimentado de assistência internacional que esteve em vigor desde o final da Segunda Guerra Mundial. A construção da paz surgiu neste contexto altamente fluido e provou ser um conceito particularmente útil na medida em que superou os limites das ortodoxias da Guerra Fria.

Inicialmente, a construção da paz foi apresentada em Uma agenda para a paz no âmbito de uma progressão de intervenções discretas que iam do restabelecimento e da manutenção da paz à construção da paz no pós-conflito. No entanto, na prática, os atores internacionais depressa se confrontaram com o facto de os conflitos pós-Guerra Fria não serem unilineares na sua natureza; nem poderem ser abordados sequencialmente. Reconhecendo as limitações de mandatos fragmentados e das departamentalizações institucionais, os primeiros construtores da paz começaram a trabalhar no nexo ainda inexplorado entre a ajuda humanitária, o desenvolvimento e a segurança (Jenkins, 2013; Tschirgi, 2004). Indo além das perspetivas centradas no Estado, um número crescente de atores internacionais procurou lidar com os conflitos intraestatais através de novas abordagens multissetoriais, incluindo operações de paz multidimensionais. A nova agenda de construção da paz oferecia uma oportunidade invulgar para a ação multilateral inovadora num momento em que as políticas e os instrumentos da Guerra Fria há muito estabelecidos eram claramente insuficientes para resolver os conflitos 
intraestatais e as guerras civis. Assim, na década posterior à Guerra Fria, a construção da paz anunciou uma nova era na cooperação internacional e na assistência multilateral. À medida que diversos atores a trabalhar em direitos humanos, assuntos humanitários, resolução de conflitos, manutenção da paz ou desenvolvimento se envolveram em países afetados por conflitos, verificou-se uma proliferação de atividades, projetos, programas e políticas na interseção da segurança e do desenvolvimento que, no seu conjunto, veio a ser conhecida como construção da paz. ${ }^{3}$

Não obstante a sua forte retórica internacionalista, a construção da paz era essencialmente um projeto ocidental e foi implementada principalmente através do sistema existente de organizações internacionais, agências de doadores e várias organizações governamentais e não governamentais. Embora extremamente fragmentado, ad hoc e experimental na natureza, a agenda internacionalmente orientada de construção da paz foi em larga medida influenciada pelo conceito de paz liberal e encontrou ressonância no etos liberalizador dos assuntos internacionais do pós-Guerra Fria (Baranyi, 2008; Richmond, 2009; Tadjbakhsh, 2011). De Moçambique e do Camboja a El Salvador, os atores internacionais apoiaram políticas e programas que refletiam um forte compromisso com os valores liberais, incluindo a boa governação, o Estado de direito, direitos humanos, participação política, eleições livres e justas, igualdade de género, mercado livre, transparência e prestação de contas.

Não é de estranhar que as aspirações liberais da construção da paz internacional não tenham encontrado terreno fértil em países com ordens políticas altamente conflituantes e problemas socioeconómicos profundamente enraizados. À medida que os ensinamentos dos países afetados por conflitos começaram a surgir, o otimismo da década de 1990 deu lugar a sérias preocupações sobre a adequação e a sustentabilidade do projeto de construção da paz liberal impulsionado a partir do exterior. Entretanto, um número crescente de estudos de avaliação foi determinante na revelação dos fracos resultados alcançados pelos esforços de construção da paz (Goodhand, 2001; Smith, 2004; Sørbø et al., 1998; Waller, 2000). Assim, à medida que a necessidade de assistência internacional para a construção da paz continuou a aumentar, foram surgindo sérias dúvidas sobre a sua eficácia e o seu impacto.

Face às origens práticas da construção da paz, a comunidade académica acabou por chegar mais tarde ao terreno. No entanto, à medida que os

\footnotetext{
${ }^{3}$ Neste artigo, o termo "construção internacional da paz" abrange operações de paz multidimensionais, incluindo o restabelecimento e a manutenção da paz como parte da agenda mais ampla da construção da paz.
} 
testemunhos provenientes do terreno se iam acumulando, verificou-se uma rápida proliferação da bibliografia académica na interseção da teoria, das políticas e da prática. Bibliografia esta que é tão rica como diversificada. No entanto, existem duas correntes distintas que representam perspetivas divergentes sobre a construção da paz: a abordagem convencional da resolução de problemas e a abordagem crítica (Newman et al., 2009). A abordagem convencional aceita a construção da paz como uma parte essencial da agenda internacional liberal da era pós-Guerra Fria e concentra-se principalmente nas deficiências existentes na sua aplicação. Os investigadores têm documentado de forma convincente as limitações da construção da paz internacional, que vão desde a ausência de uma estratégia coerente e de recursos adequados à falta de coordenação entre os atores externos que desempenham papéis de destaque em países afetados por conflitos. Este corpo bibliográfico veio a ser conhecido como a abordagem convencional da "resolução de problemas", uma vez que defende a perspetiva de que as limitações da construção da paz podem ser aliviadas através de políticas, práticas e instituições mais eficazes (Newman et al., 2009; Tadjbakhsh, 2011).

A bibliografia sobre a resolução de problemas tem sido extremamente influente. $\mathrm{Na}$ conceção e execução das sucessivas intervenções de consolidação da paz, os decisores políticos e os profissionais têm tirado partido das perspetivas de um corpo cada vez maior de estudos académicos operacionais e de avaliação. Simultaneamente, tem havido importantes iniciativas de reforma, incluindo a criação de uma nova "arquitetura de construção da paz" da ONU (que integra a Comissão de Consolidação da Paz, o Fundo para a Consolidação da Paz e o Gabinete de Apoio à Consolidação da Paz), a adoção de novas orientações para as políticas de manutenção e construção da paz, e uma maior atenção às questões relacionadas com a sua aplicação (Cutillo, 2006; Tschirgi, 2004). Enquanto isso, dados de contextos nacionais concretos permitiram aos investigadores e académicos levar a cabo análises comparativas entre o que funciona e o que não funciona em diferentes ambientes. Em resultado disso, tem havido uma considerável sinergia e influência mútua entre políticas, prática e investigação, o que deu origem a uma comunidade epistémica distinta em torno da construção da paz convencional.

Uma das questões que ganharam uma maior atenção entre os decisores políticos, bem como entre a comunidade de investigação associada à resolução de problemas, foi a separação entre as abordagens internacionais e locais para a construção da paz. Embora tenha sido repetidamente afirmado que a construção da paz é um processo de origem interna, as estratégias de construção da paz foram frequentemente concebidas e executadas por atores externos apenas com uma consulta limitada ou superficial aos seus 
homólogos nacionais. Embora não fosse claro o que envolvia a apropriação local, os mantras da apropriação e da parceria, da coordenação e da coerência, da harmonização e do alinhamento tornaram-se rapidamente os princípios indispensáveis para o discurso e a prática dominantes da construção da paz (Chesterman, 2007; Donais, 2009). A questão da apropriação local era particularmente relevante para a Comissão de Consolidação da Paz da ONU, uma vez que passou a estar envolvida na Serra Leoa e no Burundi, que foram os primeiros países na sua agenda.

No entanto, as reformas em curso não se traduziram prontamente em resultados mais eficazes na construção da paz. Uma vez que a distância entre as ambições e o desempenho real da construção da paz internacional se manteve apesar de importantes inovações, surgiu um corpo paralelo de bibliografia que veio questionar os principais pressupostos da construção da paz internacional. Operando inicialmente à margem do discurso dominante, esta abordagem crítica à construção da paz tem vindo a conquistar terreno de forma constante. A nova bibliografia crítica desafia a própria base da agenda liberal de construção da paz ao levantar questões sobre o tipo de paz que está a ser construído e ao questionar a sustentabilidade do modelo promovido pela comunidade internacional (Richmond, 2006; Tadjbakhsh, 2011). Após o 11 de Setembro, este debate foi ainda mais afetado pela combinação da construção da paz com as preocupações internacionais relativamente à segurança, com o início do combate global contra o terrorismo (Tschirgi, 2013). Â medida que a construção da paz começou a exigir um aumento da dependência do uso da força, os analistas começaram a questionar as motivações e os objetivos da agenda internacional de construção da paz e a viabilidade do modelo liberal de construção da paz nas sociedades não ocidentais afetadas por conflitos (Baranyi, 2008; Tschirgi, 2013). Houve mesmo quem defendesse que as estratégias dominantes de construção da paz não eram apenas inadequadas para resolver os multifacetados e estruturais problemas com que os países saídos de conflitos se confrontavam, como poderiam inclusivamente contribuir para a sua perpetuação.

Assim, as atenções dos investigadores críticos voltaram-se para as questões normativas e estruturais subjacentes - e não para os desafios operacionais - que afligiam a construção da paz internacional. Entre outras, essas questões incluíam as assimetrias de poder, quer ao nível global, quer interno, as motivações económicas dos conflitos e os impactos das políticas dos principais Estados e organizações internacionais sobre os conflitos nas regiões periféricas. Ao contrário da abordagem pragmática convencional, que procurava soluções para melhorar a eficácia da construção da paz, a abordagem crítica defendia que as estratégias promovidas pela construção 
da paz liberal estavam erradas uma vez que não se encontravam em sintonia com as realidades, necessidades e aspirações locais e não tinham em conta a questão central da legitimidade (Newman et al., 2009; Pugh, 2013; Tadjbakhsh, 2011).

As perspetivas quer da abordagem convencional, quer da crítica inspiraram importantes debates e controvérsias não resolvidas sobre o que constitui uma paz sustentável e como pode esta ser alcançada. Na verdade, ambas as abordagens são consideravelmente mais diversas e heterogéneas do que aquilo que se sugere na breve revisão que se acabou de fazer. No entanto, elas convergem na preocupação que partilham pelas consequências, intencionais ou não, da construção da paz internacional nas sociedades afetadas por conflitos e na necessidade de a construção da paz se basear nas realidades locais. Ao promover uma agenda liberal de construção da paz, a abordagem dominante tem apelado a estratégias internacionais diferenciadas, com base em esforços determinados pelo contexto, com sustentação local e sensíveis ao conflito, em colaboração com parceiros locais. Por seu lado, académicos críticos têm progressivamente vindo a argumentar que, na melhor das hipóteses, a construção da paz pode produzir resultados híbridos em resultado do encontro entre a agenda liberal ambicionada e as dinâmicas políticas complexas em países afetados por conflitos. Em suma, não obstante a retórica estereotipada de muitos documentos sobre políticas, existe um crescente entendimento de que a construção da paz não é uma empresa monolítica mas, sim, um processo confuso com resultados imprevisíveis (Newman, 2009: 46). A essa luz, o conceito de hibridismo oferece um interessante prisma para reexaminar a viabilidade da agenda de construção da paz duas décadas após ter obtido aceitação generalizada.

Especificamente, o hibridismo fornece uma nova perspetiva para compreender as relações assimétricas, mas interdependentes entre a gama variada de atores externos e internos envolvidos na construção da paz, ao mesmo tempo que levanta a questão central da legitimidade que se verifica nessa mesma construção (Aguirre e van der Borgh, 2010; Boege et al., 2009). Com origem nas ciências naturais, há muito tempo que o hibridismo é usado nas ciências humanas e sociais para desafiar os discursos e as práticas hegemónicas. Não existe uma definição comummente aceite de hibridismo na sua aplicação à construção da paz. Na verdade, o conceito e a sua utilidade são bastante contestados. No entanto, o hibridismo na construção da paz pode ser descrito como o processo e o resultado da contestação entre os diferentes sistemas normativos e sociopolíticos que levou à criação de um novo sistema que é suficientemente distinto dos seus progenitores. 
Por outras palavras, o hibridismo ocorre na interação disputada entre as agendas internas e internacionais de construção da paz.

\section{Reenquadrar a construção da paz: da paz liberal ao hibridismo}

Há duas razões principais pelas quais o conceito de hibridismo tem encontrado cada vez mais terreno fértil na construção da paz. Primeiro, capta a heterogeneidade e diversidade no seio das sociedades à medida que estas entram em contacto com o projeto internacional de construção da paz. Em contraste com a suposição implícita de que as sociedades afetadas por conflitos são tabula rasa que estão abertas a modelos de paz externamente induzidos, o conceito de hibridismo reconhece a existência de ordens políticas internas com regras e reivindicações rivais de autoridade, poder e legitimidade que interagem e coexistem com várias misturas de tradições modernas, indígenas, formais e informais. Em segundo lugar, o hibridismo admite que os esforços para construir a paz liberal coexistam com atores nacionais e sejam mediados por estes, através de "uma mistura complexa de resistência local, cooptação, cumprimento e rejeição" (Liden et al., 2009: 588).

Assim, o hibridismo é um ponto de partida útil para novas formas de conceptualizar a construção da paz. Desloca o foco da construção da paz da eficácia para a legitimidade, ligando-a mais diretamente ao interesse crescente na construção do Estado, ao mesmo tempo que desafia a perspetiva da construção do Estado limitada às suas instituições formais. Como já foi observado, o desafio consiste em

procurar formas e meios de criar a adaptação mútua positiva do Estado e dos mecanismos e instituições consuetudinárias não-estatais ou da sociedade civil - que, na prática, não são de todo domínios isolados, mas elementos de um contexto sociopolítico local particularmente confuso - para que possam emergir novas formas de comunidade política que sejam mais capazes, eficazes e legítimas do que aquelas geradas por modelos ocidentais de Estado concebidos de forma restrita. (Boege et al., 2009: 608)

Igualmente importante é o facto de que permitir o hibridismo tem implicações na adaptação da ajuda externa para a construção da paz. O hibridismo não se limita a implicar a necessidade de uma maior colaboração, alinhamento, harmonização e sincronização de esforços entre os atores externos e internos - embora estes possam servir para resolver algumas das falhas atuais das estratégias dominantes de construção da paz. Em vez disso, o hibridismo sugere que as relações de construção da paz não podem ser reduzidas às de doadores $v s$. destinatários ou nacionais $v s$. atores internacionais, mas que devem ser vistas como parte de um processo altamente 
político de negociação de múltiplas agendas - muitas vezes concorrentes no amplo espectro de atores internos e externos (Barnett e Zurcher, 2009). Como Boege et al. referem:

As possibilidades de influenciar externamente estruturas de governação podem ser reexaminadas, deslocando o foco dos modelos restritos de construção do Estado para o entendimento e envolvimento com atores e instituições não-estatais em ordens políticas híbridas, numa tentativa de formar comunidades políticas não na ignorância dos mundos da vida locais - ou mesmo em oposição a eles -, mas integrando-se neles. Atualmente, no entanto, os doadores e outros atores externos tendem a assumir o papel de ensinar aos políticos e às pessoas dos chamados Estados frágeis a forma de adotar as instituições estatais ocidentais de forma eficaz. Fala-se muito de apropriação, mas frequentemente isso não passa de mera retórica. $\mathrm{Na}$ verdade, a população local deve "apropriar-se" daquilo que quem vem de fora thes diz - "a apropriação local significa claramente a 'sua' apropriação das 'nossas ideias'. (Boege et al., 2009: 611)

Por outras palavras, o hibridismo diz respeito quer aos processos, quer aos resultados da construção da paz e requer uma mudança de foco, passando dos modelos liderados externamente para processos políticos abertos, continuamente negociados e conduzidos a partir de dentro com resultados incertos e imprevisíveis. Uma mudança de foco deste tipo tem de ser dinâmica, sensível ao conflito e com base local, caso pretenda evitar ser dominada pelos interesses instalados, assim como mudar as realidades nos países saídos de conflitos.

No entanto, o conceito de hibridismo, como o da própria construção da paz, tem até agora encontrado pouca adesão entre os analistas e profissionais nos países afetados por conflitos - particularmente no Sul - refletindo a enraizada assimetria Norte-Sul na construção da paz. De facto, as perspetivas analíticas que até à data têm informado as políticas e práticas da construção da paz têm sido largamente dominadas por académicos do Norte/ /ocidentais. Com poucas exceções, a construção da paz não existe como campo de estudo específico nas universidades e instituições de investigação do Sul. Isto deve-se em grande medida - embora não exclusivamente à fraqueza geral das ciências sociais e à ausência de um lar académico natural para um campo transdisciplinar como é a construção da paz. Os investigadores e os profissionais do Sul que trabalham em problemas como a reforma agrária, gestão de recursos naturais, recuperação com base na comunidade, mecanismos de justiça tradicional ou governação democrática não rotulam necessariamente o seu trabalho genericamente como construção da paz. Como resultado, existe apenas um corpo limitado de estudos académicos 
locais sobre a construção da paz que serve de contrapeso aos discursos dominantes de construção da paz no Ocidente. Ao invés, os académicos do Sul - especialmente de países afetados por conflitos - têm-se envolvido amplamente em debates com origem no Ocidente. Embora as políticas e práticas ocidentais tenham sido fortemente criticadas pelos académicos do Sul, há um défice de esforços sistemáticos que articulem quadros analíticos que permitam fazer um contrabalanço. A inexistência de um corpo robusto de literatura empírica ou teórica por parte de analistas, investigadores e académicos do Sul tem contribuído para perpetuar o viés ocidental na construção da paz contemporânea (IDRC, 2008). Como foi observado por Liden et al::

Um dos aspetos notáveis dos estudos académicos sobre a construção da paz internacional contemporânea é que as vozes dos "pacificados", ou dos destinatários da paz liberal, estão com frequência ausentes. Cada vez mais há um desacordo entre aqueles que apoiam a paz liberal nas suas formas mais coercivas e aqueles que procuram dar um maior peso às questões de consentimento local, autodeterminação, identidade e sustentabilidade. (2009: 593)

Perante o facto de que os académicos ocidentais (e especialmente os proponentes da abordagem da resolução de problemas) têm vindo a exercer uma influência crescente nos círculos políticos, as perspetivas dominantes externamente enquadradas têm dominado nos estudos, políticas e práticas da construção da paz. Alguns académicos identificaram isso como um défice grave do campo, observando que levanta

questões sérias sobre o papel da academia na assistência ou reciclagem dos mantras associados das políticas através de investigação "pragmática" orientada para as políticas, que reproduz versões conservadoras da paz liberal/neoliberal, em vez de se focar em inovações teóricas, empíricas, éticas e metodológicas que visam produzir dinâmicas emancipatórias da construção da paz. (Liden et al., 2009: 588)

É neste contexto que o hibridismo pode ajudar a reenquadrar os discursos e práticas que moldaram a construção da paz nas duas últimas décadas. A questão-chave na construção da paz não se refere à validade de perspetivas e agendas internas face às externas, mas à sua interação, que tem consequências importantes. Assim, o hibridismo não é uma abstração, mas uma realidade que precisa de ser investigada empiricamente. Ao desafiar as dicotomias enganadoras de externo $v$ s. interno, formal $v s$. informal e moderno $v s$. tradicional que até agora têm caracterizado o discurso, a política 
e a prática da construção da paz, o hibridismo força uma análise rigorosa da dimensão em que os objetivos, agendas e estratégias desenvolvidas por vários atores contribuem para processos e resultados sustentáveis no terreno.

A escassez de investigação, análise e estudos sobre a construção da paz localmente produzidos em países afetados por conflitos continua a ser um sério impedimento para transformar a agenda internacional de consolidação da paz. Mas se os construtores da paz internacionais são culpados de ignorar ou subestimar as dinâmicas e os contributos locais, os construtores da paz locais são igualmente negligentes, ao fazerem uma leitura errada e confundindo as agendas e os contributos internacionais por causa da sua própria falta de conhecimentos sobre a evolução das políticas e práticas internacionais nos últimos vinte anos. Em resultado disso, o encontro do local e do internacional assenta muitas vezes em premissas falsas. Em demasiados casos, a construção da paz é reduzida a modelos técnicos com base em listas de verificação e modelos para evitar a política. Noutros casos, a construção da paz torna-se extremamente politizada, ao mesmo tempo que lhe falta um enquadramento comum em torno do qual se possam mobilizar interesses e agendas concorrentes. Para superar essas limitações, o hibridismo na construção da paz exige uma análise e uma cartografia mais sistemáticas da dinâmica do conflito por parte dos atores locais e internacionais. Mas também exige plataformas, instituições e mecanismos credíveis que possam reunir os atores locais e internacionais em torno de um quadro comum - tanto a nível do país como a nível global. Na secção seguinte, procede-se a uma breve análise de dois desses mecanismos a nível global. Ainda que seja apenas ilustrativa, essa análise pretende estimular uma reflexão crítica sobre as formas de superar o fosso existente entre os discursos, políticas e práticas locais e os internacionais.

\section{Superar o fosso a nível global}

Como se referiu anteriormente, a gestão das interações entre os diversos atores externos e internos é uma das principais preocupações na construção da paz. A forma como estas relações são percebidas, definidas e alinhadas é um aspeto essencial da construção da paz. Grande parte da literatura dominante define o envolvimento entre os atores locais e internacionais enquanto um processo de apropriação local e não como um processo complexo de negociação e contestação. Assim, considera-se que o principal mecanismo para esse envolvimento reside numa melhor coordenação através da utilização de numerosas ferramentas e estratégias. Isso pressupõe um maior grau de unidade e coerência entre os atores nacionais e os internacionais, o que acontece raramente. As discussões sobre a coordenação têm de ser 
precedidas por uma compreensão mais precisa de quem e o que deve ser coordenado e dos seus respetivos interesses e agendas. Uma vez que não se pode assumir que os atores nacionais ou internacionais partilham agendas similares ou uma visão comum sobre a construção da paz, as suas interações têm que ser intermediadas a partir do ponto de vista da construção da paz. A próxima secção analisa dois mecanismos concebidos para juntar os países afetados por conflitos com os atores internacionais de forma a identificar estratégias mais eficazes de construção da paz. Ambos constituem esforços experimentais e o seu impacto na construção da paz continua em aberto. $\mathrm{Na}$ verdade, existem sérias preocupações de que estas sejam iniciativas centradas nos Estados que não levam devidamente em conta os interesses e as agendas concorrentes, quer a nível local como internacional. No entanto, constituem inovações importantes que merecem mais atenção.

\section{A arquitetura de construção da paz da ONU}

Uma das principais reformas institucionais destinadas a gerir as relações entre os países afetados por conflitos e o sistema multilateral sob os auspícios da Organização das Nações Unidas foi a criação, na Cimeira Mundial de 2005, da chamada arquitetura de consolidação da paz das Nações Unidas. Esta arquitetura consistiu na Comissão de Consolidação da Paz (Peacebuilding Commission - PBC), no Fundo para a Consolidação da Paz (Peacebuilding Fund - PBF) e no Gabinete de Apoio à Consolidação da Paz (Peacebuilding Support Office - PBSO). Enquanto órgão intergovernamental da ONU, a PBC foi concebida como mecanismo catalisador para reparar a natureza fragmentada, dispersa e errática do apoio internacional à construção da paz, através da criação de um conjunto de novas instituições com o mandato explícito de superar essas fragilidades e responder melhor às necessidades e realidades locais (United Nations, 2000, 2004). Resumindo, a PBC (e, por extensão, o PBF e o PBSO) tinha como objetivo I) chamar a atenção para as necessidades prementes dos países saídos de conflitos; II) promover uma melhor coordenação e coerência entre a miríade de atores envolvidos na construção da paz; III) reunir recursos para a construção da paz; e IV) aumentar a base de conhecimentos para uma política e uma prática mais eficaz de construção da paz. A expectativa era de que a nova arquitetura iria servir de interlocutor, assim como de advogado, aos países afetados por conflitos na procura de apoio internacional. Além disso, estava subjacente a presunção de que, ao contrário de outros órgãos da ONU, a PBC não ficaria refém de interesses nacionais limitados, mas que lhe seria permitido guiar-se pelas necessidades dos países na sua agenda.

Infelizmente, essas expectativas foram reduzidas como consequência das resoluções fundadoras da PBC, que refletiam as profundas clivagens 
políticas nas Nações Unidas na altura. A PBC foi criada como órgão consultivo, quer para o Conselho de Segurança, quer para a Assembleia-Geral. Em resultado disso, a Comissão não tinha qualquer autoridade independente ou poder de tomada de decisão sobre outros organismos (Ponzio, 2007). Além disso, embora a intenção fosse que a Comissão "constituísse uma plataforma ágil em que todos os atores envolvidos na construção da paz num determinado contexto pudessem discutir e chegar a acordo sobre a estratégia e as prioridades comuns, durante as negociações a participação na PBC tornou-se significativamente mais fixa e formalizada" (Hearn et al., 2014: 4). Estas decisões iniciais tiveram consequências de grande alcance para as operações da PBC nos países que vieram a fazer parte da sua agenda.

Os dois primeiros países a fazer parte da agenda da Comissão foram o Burundi e a Serra Leoa. Não obstante as suas limitações intrínsecas e o significativo processo de aprendizagem, a PBC deu início a um extenso (e complicado) processo de envolvimento com os atores nacionais e outros intervenientes relevantes nesses países através do que se designou por "estratégia integrada de construção da paz" (Integrated Peacebuilding Strategy - IPBS). O processo IPBS específico de cada país destinava-se a fazer com que os diversos atores chegassem a um entendimento comum da dinâmica do conflito em cada contexto e fossem guiados pelas necessidades e prioridades identificadas em conjunto para que isso servisse de base a respostas internacionais mais eficazes. No entanto, o processo IPBS veio a interligar-se inevitavelmente com uma miríade de outros processos e mecanismos, acrescentando mais uma camada de complexidade ao envolvimento internacional com atores nacionais e locais. Talvez igualmente importante, dada a participação de 31 Estados com múltiplas agendas cruzadas que iam para além das necessidades dos países afetados por conflitos, a PBC nunca se conseguiu tornar o órgão consultivo consensual que dela se esperava (Ponzio, 2007). Além disso, dado o seu caráter intergovernamental, a PBC viu nos governos o seu principal interlocutor, não se envolvendo de forma eficaz com outros atores nacionais e locais importantes, em particular o setor não governamental.

No entanto, o processo IPBS tornou-se o principal instrumento de envolvimento da $\mathrm{PBC}$, à medida que novos países vieram a integrar a sua agenda, refletindo mais uma tendência para uma trajetória de dependência do que uma vontade de compreender melhor a dinâmica política e os desafios da construção da paz, sempre diferentes em cada contexto de conflito (Heemskerk, 2007; McCandless e Tschirgi, 2010). Na verdade, com cada adesão sucessiva à PBC - Guiné-Bissau (2007), República Centro-Africana (2008), Libéria (2010) e, finalmente, Guiné-Conacri (2011) -, a necessidade de abordagens 
diferenciadas tornou-se bastante óbvia. No entanto, cada novo país também expôs as deficiências da Comissão de Consolidação da Paz, sobretudo a sua incapacidade de responder adequadamente às dinâmicas políticas em mudança em diversos cenários de conflito.

Em 2010, na primeira revisão quinquenal da PBC foram sublinhadas muitas das suas limitações (United Nations, 2012). No entanto, os observadores também apontaram algumas conquistas iniciais, em especial no que respeita à adequação da ajuda e a uma maior coerência entre os atores internacionais. Relativamente ao Burundi, por exemplo, a PBC foi objeto de uma apreciação positiva relativamente ao envolvimento dos doadores bilaterais e das agências multilaterais para uma melhor coordenação entre a ajuda dos doadores e o governo e à obtenção de mais de 680 milhões dólares através dos seus esforços de sensibilização (Smith, 2013 apud Hearn et al., 2014). Da mesma forma, em relação à Serra Leoa, foi enaltecido o papel da PBC no apoio político prestado a Von der Schulenburg, Representante Executivo do Secretário-Geral, nos seus esforços para coordenar uma estratégia mais coerente no país (ibidem). No entanto, os resultados contrastantes dos países que integram a agenda da PBC em 2014 são reveladores: embora nenhum dos seis países esteja livre do risco de novos conflitos, houve retrocessos graves na Guiné-Bissau e na República Centro-Africana. Na Guiné-Bissau deu-se um golpe militar em 2012, enquanto a República Centro-Africana continua a viver uma crise prolongada. Talvez ainda mais revelador seja o facto de a PBC, enquanto instrumento eficaz de envolvimento internacional, ser regularmente ignorada relativamente a muitos outros países afetados por conflitos, como o Afeganistão, a Costa do Marfim e o Sudão do Sul.

Vai para além do âmbito deste artigo proceder a uma avaliação da eficácia e do impacto da PBC. À medida que se aproxima o $10{ }^{\circ}$ aniversário da criação da Comissão de Consolidação da Paz, surgirão sem dúvida muitos estudos que avaliem o contributo da Comissão para os processos e resultados da construção da paz. ${ }^{4}$ No entanto, é importante reconhecer que o processo de IPBS tinha por objetivo gerar modalidades diferenciadas de envolvimento que permitissem uma maior capacidade de resposta às dinâmicas locais. Igualmente importante é o facto de que a PBC tem proporcionado uma plataforma em que os diversos atores governamentais e intergovernamentais podem harmonizar as suas intervenções de construção da paz de modo a que melhor se adequem às condições políticas no terreno. Em suma, a PBC reflete um entendimento crescente da necessidade de um mecanismo que proporcione o apoio atempado a processos políticos cruciais entre os

${ }_{4}^{4}$ A revisão quinquenal da $\mathrm{PBC}$ incidiu sobre questões institucionais. 
principais intervenientes, ainda que a política institucional da ONU tenha até agora estado contra a atribuição à $\mathrm{PBC}$ de um papel de maior relevância (Berdal, 2009; Jenkins, 2013).

No entanto, uma vez que o mandato da PBC está atualmente limitado a apenas seis países na sua agenda, é evidente que continua a existir necessidade de outros mecanismos formais e informais que possam facilitar o alcance e a amplitude do envolvimento entre atores locais e internacionais. Além da PBC, os mecanismos atuais de envolvimento entre estes atores continuam em grande parte a revelar-se ad hoc, inadequados e, muitas vezes, impulsionados pelos Estados mais poderosos. Curiosamente, o interesse crescente pela segurança manifestado pelas grandes potências relativamente à fragilidade do Estado e à construção deste, levou à criação de um mecanismo inovador que promete contornar a política da ONU através do Novo Acordo.

\section{O Novo Acordo para o Envolvimento em Estados Frágeis}

O Novo Acordo para o Envolvimento em Estados Frágeis (doravante, Novo Acordo) é um compromisso entre um grupo de 18 países, designado por $\mathrm{g} 7+$, e os seus parceiros internacionais para o desenvolvimento, que foi adotado em Busan, na Coreia do Sul, em novembro de 2011, durante o 4. ${ }^{\circ}$ Fórum de Alto Nível sobre a Eficácia da Ajuda. Ao contrário da PBC, que é um órgão político, o Novo Acordo concentra-se na relação entre países doadores e beneficiários no que se refere à ajuda. Constituído em 2010, o g7+ é um coletivo de países - identificados como "frágeis e/ou em situações afetadas por conflito" - comprometidos com a partilha de experiências, estratégias de desenvolvimento e a defesa e promoção da construção da paz e de Estados de uma forma mais eficaz. Em virtude do papel ativo assumido pelo g7+, que tem o seu secretariado em Díli, em Timor-Leste, o Novo Acordo promete reforçar a nível internacional a voz dos países frágeis e afetados por conflitos.

O Novo Acordo assenta na premissa de que a ajuda ao desenvolvimento só pode apoiar a construção da paz de forma eficaz se deslocar o foco da anterior "transferência de doador a recetor de modelos, políticas e práticas - ou através de abordagens planificadas à reforma institucional - para uma parceria equitativa entre governos e parceiros de desenvolvimento com base no diálogo e na colaboração" (IDPS, 2014: 8). Assim, neste Acordo afirma-se que a ajuda deve concentrar-se nas prioridades corretas, em processos de transição promovidos e liderados pelos próprios países e em recursos que são direcionados para o reforço das capacidades e dos sistemas locais.

No Novo Acordo, identificaram-se cinco Objetivos para a Construção da Paz e para a Construção do Estado (Peacebuilding and Statebuilding Goals - PSG) 
como base para possibilitar o progresso em direção aos Objetivos de Desenvolvimento do Milénio (ODM) e para orientar os esforços e os recursos nacionais e internacionais. Os PSG consistem em políticas legítimas que visam promover a resolução de conflitos e acordos inclusivos; segurança, para estabelecer e reforçar a segurança dos cidadãos; justiça, para resolver injustiças e aumentar o acesso à justiça; bases económicas, para criar emprego e melhorar os meios de subsistência; e receitas e serviços, para gerir e reforçar a capacidade para prestar serviços responsáveis e justos. ${ }^{5}$

No Novo Acordo estabeleceram-se novos termos de envolvimento para apoiar as transições promovidas e lideradas pelos próprios países para a saída de situações de conflito e fragilidade, que ficaram conhecidos pelo acrónimo FOCUS. O FOCUS inclui avaliações de fragilidade, uma visão/ /um plano, acordos entre os principais intervenientes, recurso aos PSG para monitorização do progresso e apoio ao diálogo político e à liderança. O Novo Acordo também descreve uma série de compromissos que visam alcançar melhores resultados, que designa por TRUST (transparência, risco partilhado, utilização e reforço dos sistemas do país, reforço das capacidades e ajuda atempada e previsível [transparency, risk sharing, use and strengthening of country systems, strengthening capacities, and timely and predictable aid]).

Desde o seu lançamento, em 2011, tem havido uma intensa atividade para operacionalizar os objetivos consagrados no Novo Acordo em sete países-piloto: Afeganistão, República Centro-Africana, República Democrática do Congo, Libéria, Serra Leoa, Sudão do Sul e Timor-Leste. Este processo tem sido acompanhado de esforços concertados para desenvolver novas ferramentas metodológicas e analíticas com vista à monitorização do progresso registado com o Novo Acordo. Reconhecendo que muitas das estratégias de construção da paz se baseiam em ferramentas de análise de conflitos que foram preparadas por analistas e especialistas externos, o Novo Acordo requer estudos, designados por "avaliações de fragilidade", liderados pelos próprios países sobre as causas e características das fragilidades e as fontes de resiliência. Estes devem servir como base para a estratégia "uma visão/um plano" dos objetivos FOCUS. Estas avaliações periódicas devem ser preparadas pelos intervenientes nacionais principais e por atores não-estatais com base numa metodologia harmonizada, incluindo um espectro de fragilidade, para serem desenvolvidas pelo $\mathrm{g} 7+\mathrm{e}$ apoiadas pelos parceiros internacionais.

Como preparação para um encontro do Grupo de Trabalho de Implementação, na Serra Leoa, em junho de 2014, com o objetivo de monitorizar

\footnotetext{
${ }_{5}$ Para uma extensa documentação sobre o Novo Acordo, consultar http://www.newdeal4peace.org.
} 
o progresso em direção aos PSG, foi elaborado um relatório para avaliar as principais realizações do Novo Acordo com base em dois inquéritos e em informações provenientes de outras fontes. O relatório identifica as principais realizações do Novo Acordo da seguinte forma:

Primeiro, o diálogo entre governos, doadores e sociedade civil revela progressos, tendo-se tornado mais inclusivo ao longo dos últimos três anos em alguns países. Isto levou a que se prestasse mais atenção à construção da paz e à construção do Estado. [...] Segundo, a ajuda está a tornar-se mais transparente. Os resultados do inquérito demonstram que os doadores estão a levar este aspeto a sério, melhorando os seus sistemas e padrões globais para a elaboração de relatórios sobre a ajuda ao desenvolvimento. [...] Terceiro, o financiamento dos doadores está a tornar-se mais integrado. (IDPS, 2014: 9-10)

No entanto, o relatório também refere que, embora estes resultados apontem para uma maior liderança nacional e algumas mudanças no comportamento dos doadores, estas "ficam significativamente aquém da 'mudança de paradigma' que se espera do Novo Acordo. A mudança é lenta e não sistémica" (IDPS, 2014: 10).

No papel, o Novo Acordo parece ser um passo em frente no sentido de dar mais voz ao g7+ na definição da agenda, assim como no planeamento estratégico, corrigindo as atuais relações assimétricas entre países afetados por conflitos e países frágeis e os seus parceiros de desenvolvimento. O Novo Acordo tem um potencial considerável para o conseguir, desde que traga para o debate uma análise politicamente informada e com origem local e uma avaliação das necessidades com base em consultas sérias junto dos principais intervenientes a nível nacional. Como referido no relatório do IDPS:

A importância específica do Novo Acordo é o facto de estabelecer um enquadramento que visa assegurar que a procura de uma solução política aceitável é inclusiva e tem por base um entendimento partilhado, quer dos vetores de fragilidade profundamente enraizados e dos atuais, quer das fontes de resiliência. Este tipo de abordagem garante que o diálogo não se limita a um pacto entre a elite para pôr termo ao conflito. O Novo Acordo procura manter um diálogo dinâmico e num patamar elevado, indo para além de um mero acordo de paz, direcionando os esforços nacionais e internacionais para a reconstrução do país de uma forma mais resiliente. (2014: 21-22)

Atualmente, não é claro que seja isso que está realmente a acontecer. Muitas das ferramentas e dos quadros analíticos que estão a ser utilizados parecem imitar os seus homólogos internacionais. Além disso, apesar de 
se reforçar constantemente que as análises determinadas pelo contexto específico de cada país eram uma forma de prevenir conflitos e fragilidades, dois países do g7+, a República Centro-Africana e o Sudão do Sul, estão envolvidos em violentos conflitos civis e partes da Somália continuam a apresentar elevados níveis de insegurança e conflito. Assim, o Relatório de Monitorização de 2014 afirma francamente:

[...] o Novo Acordo não foi capaz de desempenhar um papel fundamental na antecipação de riscos e no apoio a potenciais estratégias de mitigação na República Centro-Africana e no Sudão do Sul. Nem proporciona atualmente um enquadramento para o diálogo entre os parceiros, ou para a identificação de caminhos futuros como forma de sair do conflito.

Em vez disso, a implementação do Novo Acordo parece principalmente focada na realização de processos técnicos e em apoiar o diálogo técnico sobre questões como a eficácia e os resultados da ajuda. Aa avaliações de fragilidade, quando realizadas, têm-se debatido para ganhar espaço político para as suas conclusões, como mostra a adoção limitada dos PSG na programação nacional e a ausência de uma abordagem ao nível de toda a administração pública. Em segundo lugar, as abordagens dos doadores ao risco continuam a centrar-se no risco fiduciário e no risco ao nível dos projetos, com pouca atenção prestada relativamente à utilização dos seus programas para apoiar as estratégias de mitigação do risco contextual e político. Isto apesar de se terem verificado mudanças relevantes nas políticas de risco nas sedes dos doadores. (IDPS, 2014: 22)

\section{O relatório adverte ainda que a}

abordagem atual à implementação do Novo Acordo apresenta uma série de riscos, tal como: ausência de apropriação local exceto nas instituições centrais do Novo Acordo; desenvolvimento de processos e instrumentos centrados nos doadores em vez de serem liderados pelos próprios países; proliferação de processos paralelos em ambientes já altamente fragmentados; e falta de adaptação aos vários contextos com que se confrontam os países do g7+, incluindo situações de conflito e de extrema fragilidade. (IDPS, 2014: 24)

Apesar das suas limitações, e tal como a Comissão de Consolidação da Paz, o g7+ e o Novo Acordo abriram um novo processo que merece uma monitorização mais próxima. Curiosamente, no entanto, constata-se que a partir de 2011 surgiu uma clivagem entre a PBC e o IDPS "em grande parte sobre a influência e a autoridade na política global de construção da paz” (Hearn et al., 2014: 7). 
Alguns Estados-Membros da PBC têm expressado preocupações relativamente a uma agenda dominada pelo Ocidente e levada a cabo pelos doadores da OCDE no IDPS, que "subordinam o desenvolvimento a preocupações de segurança” (ibidem). No entanto, a PBC não tem conseguido uma resposta institucional para trabalhar com os países do g7+ e com o IDPS. Como referem Hearn et al:: "O resultado potencial é uma rede cada vez maior, dominada pelos doadores, de 'acordos' de construção da paz e de ajuda atribuída no terreno sem a concordância de todos os poderes relevantes; e uma $\mathrm{PBC}$ que corre o risco de ser marginalizada relativamente a grande parte da ação no terreno" (2014: 7). A realidade é que os mecanismos intergovernamentais como a PBC e o IDPS estão inevitavelmente limitados pelos seus mandatos institucionais, que se lutam contra uma transformação mais radical das relações assimétricas entre os atores locais e os internacionais, muito menos irão dar origem a um paradigma completamente novo de construção da paz. No entanto, é também importante reconhecer que a própria agenda de construção da paz já está toda ela sob uma pressão considerável, tendo em conta um contexto da paz e da segurança internacionais que se encontra em mudança desde o 11 de Setembro de 2001 (Tschirgi, 2013).

\section{Conclusão}

Como as secções anteriores demonstraram, existem desfasamentos nítidos entre uma quantidade inumerável de atores locais e internacionais no que respeita aos seus entendimentos e abordagens à construção da paz, o que, por sua vez, contribui para os resultados diversos e contrastantes da construção da paz. Aceitar o hibridismo como uma realidade requer uma melhor compreensão dos interesses, capacidades, necessidades e prioridades de todos os atores envolvidos na construção da paz. Até à data, a teoria, a política e a prática da construção da paz têm sido atrasadas pela ausência de perspetivas sólidas de "dentro para fora" sobre a construção da paz. $\mathrm{Na}$ última década, produziu-se um corpo considerável de estudos de caso sobre a construção da paz, que proporcionou análises aprofundadas de conflitos em diversos contextos e examinou as realizações e limitações da construção da paz internacional - ainda que principalmente a partir das perspetivas de analistas e atores externos.

Neste artigo, procurou-se apresentar uma breve visão geral do projeto de construção da paz internacional e debates importantes na literatura sobre a construção da paz relativamente às principais características e limitações desse projeto; introduziu-se o conceito de hibridismo como forma de alicerçar os esforços internacionais em dinâmicas locais, a fim de garantir processos e resultados mais sustentáveis; e analisaram-se dois mecanismos 
principais que procuram superar o fosso entre as abordagens locais e internacionais para a construção da paz. Nele, defendeu-se que a construção da paz envolve a interação complexa entre múltiplos atores internos e externos que contribuem para resultados diversificados. A premissa subjacente tem sido a de que a incorporação de perspetivas locais não só contribuiria para o reforço da investigação, da política e da prática da construção da paz, mas que serviria também como corretivo para os atuais discursos estilizados e estereotipados sobre a construção da paz.

Como se mencionou atrás, a construção da paz liberal dominante centrou-se de forma restrita na reforma das práticas atuais. Liden et al. defendem que

talvez seja preciso investigar formas não apenas de ampliar a sua responsabilidade moral em relação ao cidadão ou sujeito ou o outro não liberal, mas de se envolver com outras ontologias e epistemologias, provavelmente não-ocidentais/"modernas". É preciso encontrar formas de construir este confronto ou envolvimento no próprio processo de construção da paz, a fim de reconstruir uma forma de construção da paz politicamente mais hibridizada e, seguramente, uma que melhor represente e respeite os direitos e necessidades das sociedades e comunidades pós-conflito. Também é necessária uma reflexão sobre a necessidade de um contrato social internacional entre os construtores da paz, funcionários internacionais, soldados, trabalhadores humanitários, pessoal das ONG, especialistas em desenvolvimento e uma série de outros especialistas e administrações, e todos os destinatários da construção da paz (e não apenas as poderosas elites locais), na ausência de qualquer contrato social nacional. (2009: 594)

A criação de novos mecanismos, como a Comissão de Consolidação da Paz e o Novo Acordo, não envolve certamente uma transformação radical do atual paradigma de construção da paz. No entanto, eles oferecem novas plataformas que permitem a chegada de vozes e abordagens diversas ao debate. Se se encontrarem suficientemente ancorados em realidades politicamente informadas e localmente fundamentadas, tais mecanismos podem ajudar a superar os enviesamentos atuais da investigação, políticas e práticas sobre a construção da paz externamente orientadas. Um remédio importante para uma construção da paz mais eficaz reside na incorporação significativa e sistemática de perspetivas, realidades, necessidades e aspirações locais na análise, na política e na prática da construção da paz, uma vez que os modelos e os processos atuais não conseguem captar a complexidade da construção da paz tal como ela é vivida em diferentes contextos. Como se defendeu ao longo deste artigo, a questão não é privilegiar um conjunto de 
analistas ou de atores em detrimento de outro. Pelo contrário, é plenamente reconhecido que a construção da paz contemporânea é - e provavelmente continuará a ser - um empreendimento comum. A verdadeira questão é como melhorar esse empreendimento através da investigação, desenvolvimento de políticas e práticas que apoiem a definição de uma agenda comum, o planeamento estratégico e a sua implementação.

Tradução de Victor Ferreira

Recebido a 23.02.2014

Aprovado para publicação a 24.07.2014

\section{Referências bibliográficas}

Anderson, Mary (1999), Do No Harm, Boulder. CO: Lynne Rienner Publishers. Aguirre, Mariano; van der Borgh, Chris (2010), "Building Peace, States and Hybrids: International Operations in Post-conflict Countries", The Broker. Consultado a $15.08 .2014 \mathrm{em} \mathrm{http://www.thebrokeronline.eu/Articles/Building-}$ peace-states-and-hybrids.

Baranyi, Stephen (org.) (2008), The Paradoxes of Peacebuilding Post-9/11. Vancouver: UBC Press.

Barnett, Michael; Kim, Hunjoon; O’Donnell, Madalene; Sitea, Laura (2007), "Peacebuilding: What is in a Name?", Global Governance: A Review of Multilateralism and International Organizations, 13(1), 35-58.

Barnett, Michael; Zurcher, Christoph (2009), "The Peacebuilder's Contract; How External Statebuilding Reinforces Weak Statehood", in Roland Paris; Timothy Sisk (orgs.), The Dilemmas of Statebuilding: Confronting the Contradictions of Postwar Peace Operations. London: Routledge, 23-52.

Berdal, Mats (2009), Building Peace after War. London: The International Institute for Strategic Studies.

Boege, Volker; Brown, Anne; Clements, Kevin; Nolan, Anna (2009), "Building Peace and Political Community in Hybrid Political Orders", International Peacekeeping, 16(5), 599-615.

Chesterman, Simon (2007), "Ownership in Theory and in Practice: Transfer of Authority in UN Satebuilding Operations", Journal of Intervention and Statebuilding, 1(1), 3-26.

Cutillo, Alberto (2006), "International Assistance to Countries Emerging from Conflict: A Review of Fifteen Years of Interventions and the Future of Peacebuilding", International Peace Academy-IPA Policy Paper, fevereiro. Consultado a 15.08.2014, em http://www.ipinst.org/media/pdf/publications/cutillo_e_rpt.pdf. 
Donais, Timothy (2009), “Empowerment or Imposition? Dilemmas of Local Ownership in Post-Conflict Peacebuilding Processes", Peace E Change, 34(1), 3-26.

Goodhand, J.; Atkinson, P. (2001), Conflict and Aid: Enhancing the Peacebuilding Impact of International Engagement: A Synthesis of Findings from Afghanistan, Liberia and Sri Lanka, London: International Alert.

Hearn, Sarah; Bujones, Alejandra Kubitschek; Kugel, Alischa (2014), The United Nations "Peacebuilding Architecture": Past, Present and Future. New York: Center on International Cooperation.

Heemskerk, Renske (2007), “The UN Peacebuilding Commission and Civil Society Engagement", Disarmament Forum, 2, 17-26.

IDPS - International Dialogue on Peacebuilding and Statebuilding (2014), New Deal Monitoring Report 2014. Document 01. Fifth International Dialogue Working Group Meeting on New Deal Implementation, 17 de junho de 2014, Freetown, Serra Leoa. Consultado a 15.08.2014, em http://www.pbsbdialogue.org/newsandevents/specialevents/RD\%201\%20New\%20Deal\%20Monitoring\%20Report\%202014\%20 FINAL.pdf.

IDRC - International Development Research Centre (2008), "International Development Research Centre and Peacebuilding Support Office Joint Conference Report", Ottawa, Canadá, 10-11 de dezembro de 2008.

Jenkins, Rob (2013), Peacebuilding: From Concept to Commission. London: Routledge. Liden, Kristoffer; Mac Ginty, Roger; Richmond, Oliver P. (2009), "Introduction: Beyond Northern Epistemologies of Peace: Peacebuilding Reconstructed?", International Peacekeeping, 16(5), 587-598.

McCandless, Erin; Tschirgi, Necla (2010), "Strategic Policy Frameworks that Embrace Mutual Accountability for Peacebuilding: Emerging Lessons in PBC and non-PBC Countries", Journal of Peacebuilding and Development, 5(2), 20-46.

Newman, Edward (2009), “Liberal' Peacebuilding debates”, in Edward Newman; Roland Paris; Oliver Richmond (orgs.), New Perspectives on Liberal Peacebuilding. Tokyo: UN University Press, 26-53.

Newman, Edward; Paris, Roland; Richmond, Olivier P. (orgs.) (2009), New Perspectives on Liberal Peacebuilding. Tokyo: UN University Press.

Ponzio, Richard (2007), "The United Nations Peacebuilding Commission: Origins and Initial Practice”, Disarmament Forum, 2, 5-16.

Pugh, Michael (2013), “The Problem-Solving and Critical Paradigm”, in Roger Mac Ginty (org.), Routledge Handbook of Peacebuilding. London: Routledge, 11-24.

Richmond, Oliver (2006), The Transformation of Peace: Peace as Governance in Contemporary Conflict Ending. London: Palgrave Macmillan.

Richmond, Oliver (2009), "Becoming Liberal, Unbecoming Liberalism: Liberal local Hybridity via the Everyday as a Response to the Paradoxes of Liberal Peacebuilding", Journal of Intervention and Statebuilding, 3(3), 324-344. 
Smith, Dan (2004), "Getting Their Act Together: Toward a Strategic Framework for Peacebuilding”. Relatório síntese do the Joint Utstein Study of Peacebuilding. Oslo: The Royal Norwegian Ministry of Foreign Affairs. Consultado a 15.08.2014, em http:// www.regjeringen.no/upload/kilde/ud/rap/2004/0044/ddd/pdfv/210673-rapp104.pdf.

Sørbø, Gunnar M.; Hauge, Wenche; Hybertsen, Bente; Smith, Dan (1998), “Norwegian Assistance to Countries in Conflict: The Lesson of Experience from Guatemala, Mali, Mozambique, Sudan, Rwanda and Burundi”. Oslo: The Royal Ministry of Foreign Affairs. Consultado a 14.08.2014, em http://www.norad.no/en/ tools-and-publications/publications/publication?key=109650.

Tadjbakhsh, Shahrbanou (org.) (2011), Rethinking the Liberal Peace: External Models and Local Alternatives. London: Routledge.

Tschirgi, Necla (2004), "Post-Conflict Peacebuilding Revisited: Achievements, Limitations, Challenges", International Peace Academy-IPA Policy Paper, outubro. Consultado a 14.08.2014, em http://www.un.org/esa/peacebuilding/Library/ Post_Conflict_Peacebuilding_IPA.pdf.

Tschirgi, Necla (2013), "Securitization and Peacebuilding”, in Roger Mac Ginty (org.), Routledge Handbook of Peacebuilding. London: Routledge, 197-210.

United Nations (1992), “An Agenda for Peace: Preventive Diplomacy, Peacemaking and Peace-keeping (Report of the Secretary-General pursuant to the statement adopted by the Summit Meeting of the Security Council on 31 January 1992)", A/47/277-S/2411. New York: United Nations. Consultado a 14.08.2014, em http://www.unrol.org/ files/A_47_277.pdf.

United Nations (2000), "Report of the Panel on United Nations Peace Operations (The Brahimi Report)". General Assembly and Security Council. Documento A/55/305-S/2000/809, 21 de agosto de 2000. Consultado a 14.08.2014, em http:// www.unrol.org/files/brahimi report peacekeeping.pdf.

United Nations (2004), “A More Secure World: Our Shared Responsibility. Report of the High Level Panel on Threats, Challenges and Change". General Assembly. Documento A/59/565, 2 de dezembro de 2004. Consultado a 14.08.2014, em http:// www.un.org/en/events/pastevents/a_more_secure_world.shtml.

United Nations (2012), 2012 Annual Report. UN Peacebuilding Support Office. Consultado a 15.08.2014, em http://www.un.org/en/peacebuilding/pbso/ pdf/2012PBSO-AnnualReport-Final.pdf.

Uvin, Peter (1999), "The Influence of Aid in Situations of Violent Conflict”. Preparado no âmbito do Development Assistance Committee Informal Task Force on Conflict, Peace, and Development Co-operation, Paris: OECD, setembro de 1999. Consultado a 15.08.2014, em http://www.oecd.org/officialdocuments/publicdisplaydocumentp $\mathrm{df} /$ ? cote $=\mathrm{DCD}(2000) 16 \&$ docLanguage $=$ En .

Waller, Peter (2000), "Lessons Learned from Evaluations: Findings from a Recent Evaluation of German Development Co-Operation in Conflict Situations in Six 
44 | Necla Tschirgi

Countries". Preparado no âmbito do seminário "After War Reconciliation and Democratisation in Divided Societies - Lessons Learned", Solstrand, Noruega, 27-29 de março. 